\title{
O PAPEL DO ESTADO E O SETOR AGROINDUSTRIAL CANAVIEIRO EM PONTA PORÃ/MS
}

\author{
THE ROLE OF THE STATE AND THE AGRICULTURAL INDUSTRY \\ CANAVIEIRO IN PONTA PORÃ/MS \\ EL PAPEL DEL ESTADO Y LA CAÑA DE AZÚCAR SECTOR \\ AGROINDUSTRIAL EM PONTA PORÄ/MS
}

\begin{abstract}
Alex Torres Domingues Doutor em Geografia pela Universidade Federal da Grande Dourados. Coordenador de tutoria do curso de Bacharelado em Administração Pública na Faculdade de Educação à Distância da Universidade Federal da Grande Dourados e Professor na Rede Municipal de Dourados. E-mail: alextdomingues@gmail.com.
\end{abstract}

\begin{abstract}
Resumo: Este trabalho tem como objetivo analisar as açóes do Estado no âmbito municipal voltada ao setor agroindustrial canavieiro no município de Ponta Porã. Ademais analisamos quais são os impactos territoriais, ambientais, econômicos e sociais da relação do Estado capitalista com o este setor envolvendo uma unidade agroindustrial localizada neste município, que é a Unidade Monteverde (Grupo Bunge y Born). A relação que o Estado tem com tal setor é histórico no país e suas açóes são sempre voltadas a atender as suas demandas para a manutenção do status quo. A metodologia utilizada neste trabalho é a pesquisa bibliográfica e documental, além de visitas à campo com realização de entrevistas.
\end{abstract}

Palavras-chave: Estado. Setor agroindustrial canavieiro. Ação estatal. Ponta Porã. Capital canavieiro.

\begin{abstract}
This work aims to analyze the actions of the State in the municipal scope directed to the agribusiness sugarcane sector in the municipality of Ponta Porã. In addition, we analyze the territorial, environmental, economic and social impacts of the capitalist state's relationship with this sector involving an agroindustrial unit located in this municipality, which is the Monteverde Unit (Bunge y Born Group). The relationship that the State has with this sector is historical in the country and its actions are always aimed at meeting its demands for the maintenance of the status quo. The methodology used in this work is bibliographical and documentary research, in addition to field visits with interviews.
\end{abstract}

Keywords: State. Sugar cane agroindustrial sector. State action. Ponta Porã. Capital of canavieiro. 
Resumen: Este trabajo tiene como objetivo analizar las acciones del Estado en el ámbito municipal orientado a la cańa de azúcar del sector agroindustrial en el municipio de Ponta Porá. Además analizamos cuáles son los impactos territoriales, ambientales, económicos y sociales de la relación del Estado capitalista con este sector involucrando una unidad agroindustrial ubicada en este municipio, que es la Unidad Monteverde (Grupo Bunge y Born). La relación que el Estado tiene con tal sector es histórica en el país y sus acciones están siempre orientadas a atender sus demandas para el mantenimiento del status quo. La metodología utilizada en este trabajo es la investigación bibliográfica y documental, además de visitas al campo con realización de entrevistas.

Palabras clave: Estado. Sector agroindustrial de cańa de azúcar. La acción del Estado. Ponta Porã. Capital de caña de azúcar.

\section{INTRODUÇÃO}

O Estado ${ }^{1}$ pode ser visto como um fenômeno histórico transitório, ou como um simples resultado do aparecimento de luta das classes sociais no período de transição da propriedade coletiva para a apropriação privada dos meios de produçáo. É uma instituição momentânea e essa instantaneidade pode levar consigo o poder organizado de uma classe para dominar outra (MARX; ENGELS, 2001).

Para Ianni (1988, p. 73), o Estado não é exclusivamente um órgão a favor da classe dominante, já que responde também, "aos movimentos do conjunto da sociedade e das outras classes sociais", além das determinaçóes das relaçóes capitalistas. De acordo com o grau de "desenvolvimento das forças produtivas, das relações de produção e das forças políticas da sociedade, o Estado pode adquirir contornos mais ou menos nítidos”, estando diretamente ligados aos interesses da burguesia.

O Estado capitalista se fundamenta nestas contradiçóes que são inerentes às tensas relaçóes de classes e procuram estabelecer a hegemonia. Assim, o Estado desorganiza as classes dominadas e organiza as classes dominantes, no entanto não atende totalmente aos seus interesses.

O presente artigo objetiva averiguar as açóes estatais em âmbito municipal voltada ao setor agroindustrial canavieiro no município de Ponta Porã, bem como, analisar os impactos territoriais, ambientais, econômicos e sociais da relação do Estado capitalista com este setor envolvendo uma unidade agroindustrial localizada neste município (Unidade Monteverde - Grupo Bunge y Born).

A metodologia utilizada neste trabalho é a pesquisa bibliográfica envolvendo as discussões

1 Quando nos referimos ao Estado, com E maiúsculo, estamos tratando da organização mais complexa das sociedades civis, que seja a sociedade política, que caracterizamos como a "sociedade civil politicamente soberana e internacionalmente reconhecida" que visa o bem comum aos indivíduos e comunidades sob sua tutela que ocupam um determinado território. E esse poder, refere-se à capacidade de influenciar decisivamente a ação e o comportamento das pessoas (ACQUAVIVA, 2000, p. 4). De acordo com Therborn (1999, p. 80), podemos distinguir três correntes principais dentro das teorias do Estado: uma corrente marxista que tem como representantes principais Nico Poulantzas, Ralph Miliband, Michael Lowy; uma segunda corrente que podemos denominar estatista, "inspirada na obra de Max Weber" e; em terceiro lugar, "uma corrente teórica que não se reconhecia como uma teoria específica do Estado", a da decisáo pública, que era "uma expansão da teoria econômica liberal aplicada ao Estado". 
sobre o Estado e o seu papel por meio de políticas públicas voltadas a atender as demandas do setor agroindustrial canavieiro. Também utilizamos a pesquisa documental através da legislação vigente, além de visitas à campo com realização de entrevistas.

As entrevistas foram realizadas entre os anos de 2014 e 2016, englobando os sujeitos que foram impactados direta e indiretamente com as açóes do Estado e sua relaçáo com o setor agroindustrial canavieiro, como fazendeiros, sem-terra, assentados, trabalhadores rurais, secretários municipais, presidentes de sindicatos que estão envolvidos com o setor, entre outros.

Para preservar a identidade destes sujeitos, foram usados apenas as iniciais dos seus respectivos nomes. Tais entrevistas foram gravadas com o objetivo de consultar e resgatar as discussóes levantadas num momento posterior para a escrita e análise realizada no presente trabalho.

\section{REFERENCIAL TEÓRICO SOBRE O ESTADO}

Entendemos que a análise do Estado capitalista feita por Poulantzas (2000, p. 158) também se faz imprescindível na atualidade, uma vez que esta apresenta o Estado como uma expressão das relaçóes de classe. Dessa forma, analisa o Estado como uma entidade não apenas de direito exclusivo de uma única classe, já que evidencia as contradiçóes que perpassam as relações de "forças entre classes" e/ou "fraçóes de classes". Portanto, o bloco que está no poder, é contraditório e dinâmico entre distintas classes e/ou fraçóes de classes, sob a hegemonia de uma delas. Por sua vez, essas contradiçóes de classe representam a base material e organizacional do Estado.

A livre mobilidade do capital entre setores, regióes e países é crucial. Com isso as barreiras à liberdade desse movimento têm de ser removidas, com exceção de áreas consideradas de interesse nacional. "A soberania do Estado com relação aos movimentos de mercadorias e de capital é entregue de bom grado ao mercado global. A competição internacional é tida como algo saudável”, pois favorece a eficiência e a produtividade, além de reduzir os preços e, dessa forma, controlar as tendências inflacionárias. Sendo assim, o Estado deve se dedicar à "redução e a negociação de barreiras", bem como "ao movimento do capital por suas fronteiras para a abertura dos mercados” (HARVEY, 2012, p. 76).

Dessa forma, produz legislações e estruturas regulatórias privilegiando as corporações e interesses específicos, como energia, agronegócios, especialmente o grupos do setor agroindustrial canavieiro, etc. Em casos de parcerias público-privadas (PPP), os governos se responsabilizam por parte dos riscos possibilitando que o setor privado fique com a maior parte dos lucros. Ás vezes, o Estado vale-se de legislaçôes repressivas para dispersar a coletividade opositora, como no caso dos movimentos sociais (HARVEY, 2012).

Dessa forma, o capital que conta com o apoio estatal para a sua reprodução, cria uma disputa entre os Estados-nação com o objetivo de apresentar o melhor modelo de desenvolvimento econômico. Isso faz com que o território atinja formas desiguais de desenvolvimento no qual umas cidades recebem apoio financeiro estatal e outras apenas vislumbram 
essa situação.

A interferência estatal, geralmente acontece na expansão das forças produtivas, com o objetivo de demonstrar ao mercado que é propício o desenvolvimento do capital em determinado local, transpondo para o lucro, toda a ação governamental, utilizando, para isso, os instrumentos de que dispóe como isençóes fiscais, créditos, financiamentos, securitização de dívidas entre outros, criando um ambiente favorável à ampliação do capital, como acontece com o setor agroindustrial canavieiro (IANNI, 2004).

Para que haja mobilidade geográfica do capital, torna-se necessário um conjunto de infraestruturas espaciais fixas e seguras funcionando efetivamente a qualquer momento. É aí que se introduz o papel do Estado como propiciador e mantenedor de um sistema bem organizado de crédito pelas instituiçóes públicas, financeiras e jurídicas, além de um conjunto de infraestruturas físicas (portos, aeroportos, rodovias, ferrovias, hidrovias, etc.), buscando assegurar as trocas comerciais². Dessa forma, visualizamos a atuação do Estado brasileiro visando a manutenção da ideologia burguesa por meio da facilitação da expansão das corporaçôes Brasil afora.

A relação que o Estado tem com o setor agroindustrial canavieiro é histórico no país e suas ações são sempre voltadas a atender as suas demandas para a manutenção do status quo. Assim, analisaremos a relação do Estado com tal setor.

\section{A RELAÇÃO DO ESTADO COM O SETOR AGROINDUSTRIAL CANAVIEIRO}

De acordo com Bray et al. (2000), o Estado intervém no setor agroindustrial canavieiro desde o período colonial. No entanto, essa intervenção se intensificou a partir dos anos de 1930, com a criação da Comissão de Defesa da Produção de Açúcar e Álcool, que logo após em 1933, se transforma no Instituto do Açúcar e do Álcool (IAA) ${ }^{3}$.

No setor agroindustrial canavieiro, houve fases distintas de intervencionismo por parte do Estado. Nas décadas de 1930 a 1960, a mediação estatal foi profunda e intensa, pois foi nesse período que se estabeleceu cotas de produção, tabelou-se preços e ditou-se as normas de comercialização, à solicitação dos próprios produtores para resolver a grave crise de superprodução de 1930. Diante disso, criou-se o Instituto do Açúcar e do Álcool (IAA),

2 Harvey (2005, p. 84), entende que "o Estado é um órgão distinto dos demais, devido: 1 - o território e sua integridade é o seu principal intuito e, ao seu conjunto de funcionários; 2 - pode dar forma e coesão mais direta às alianças regionais de classes; 3 - impóe fronteiras parcialmente seguras sobre seus limites geográficos ainda que porosos; 4 - estimula e sustenta a coerência regional estruturada relativa à produção e ao consumo e; 5 transforma-se no agente central provedor da ideologia nacionalista. Dessa forma, torna-se o centro da tendência de estabelecer alianças regionais de classes acrescentando seu próprio fundamento".

3 Segundo Bray et al. (2000, p. 14), "o IAA foi instalado como uma autarquia do governo federal, vinculada inicialmente ao Ministério da Agricultura” - passando logo depois para o Ministério da Indústria e do Comércio - "com o objetivo de dirigir, intervir, fomentar e controlar a produção de açúcar e álcool do país". Essa instituição surgiu visando "contribuir com a melhoria das condiçóes da agroindústria açucareira nacional e resolver o excedente da produçáo de açúcar como fomento do álcool combustível, através da estabilizaçáo dos preços do açúcar e da construção de novos equipamentos para as destilarias destinadas à produção do álcool”. 
para firmar o planejamento da produção. Nesse período, o açúcar tinha um grande peso sob as exportaçóes, e os riscos de mercado eram, em grande medida, regulados pelo Estado brasileiro, que garantia alguns benefícios ao setor (MORAES, 2000).

$\mathrm{Na}$ década seguinte (1970), a intervenção ainda era muito forte, pois as cotas de produção e os preços ainda estavam sendo controlados pelo Estado brasileiro, visando o crescimento das exportaçóes, principalmente do açúcar. Transcorreram na referida década, alguns programas objetivando "a melhoria da produtividade e modernização da área agrícola e do parque industrial, além de incentivos para relocalização e fusôes das unidades" canavieiras. Também, surgiu o Programa Nacional do Álcool (Proálcool), com incentivos à produção de álcool anidro, normatizando a comercialização e produção e preservando os produtores dos riscos de mercado (MORAES, 2000, p. 53).

Já na década de 1980, houve a redução da intervenção estatal, uma vez que, os recursos governamentais para programas de investimentos começam a se esgotar. Neste período, houveram destilarias que contavam com tais recursos que não vieram, levando-as à estagnação, pois náo puderam finalizar seus projetos. Ainda no final dessa década (mais precisamente em 1989), as exportaçóes de açúcar, que até aquele momento eram realizadas pelo IAA, foram privatizadas (MORAES, 2000).

No ano de 1988, durante a redemocratização do país, abriu-se um caminho para o total controle do Estado brasileiro e uma completa influência da economia brasileira pelo capital financeiro internacional, sujeitos a uma pressão clara dos representantes políticos desse capital, como o Fundo Monetário Internacional (FMI), o Banco Mundial e o governo dos Estados Unidos, além dos gestores econômicos como os bancos e corporaçóes internacionais (SAES, 2001).

No início dos anos 1990, fase dos carros movidos a álcool hidratado, no qual a demanda deste produto se torna mais elevada pela utilização em grande quantidade do combustível, houve uma crise de fornecimento do produto, prejudicando o andamento do Proálcool. Dessa forma, tornava-se imprescindível a necessidade do setor a uma nova forma de intervenção estatal, uma vez que havia um descompasso entre a oferta e a demanda do produto, causado pelo próprio setor com a fase de intervencionismo estatal (MORAES, 2000).

A partir daí a intervenção estatal foi reduzida consideravelmente no que tange à liberação do preço e a comercialização. Para o setor agroindustrial canavieiro, a ação estatal se faz necessária, para a obtenção de privilégios que eram fornecidos a este, exigindo outro tipo de ação do Estado. Esse processo favoreceu, em grande medida, a fusão das empresas nacionais às corporaçóes e/ou grupos internacionais.

A aliança entre o setor agroindustrial canavieiro e o Estado, mesmo que seja mais distante do que no passado, é nítida e traz muitos benefícios ao primeiro, pois o Estado defende as condiçôes gerais do modo capitalista de produção, que no setor canavieiro se evidencia nos altíssimos valores para financiamentos de plantas industriais, de reforma de áreas plantadas, compra de máquinas e equipamentos, etc. (IANNI, 1996).

O fato é que o Estado apresentou uma relação mais próxima com o setor canavieiro no Nordeste brasileiro promovendo a manutenção do status quo, além do fortalecimento da 
relação clientelista/coronelista (usineiro x Estado). Essa relação demonstra que o Estado está atendendo uma fração da burguesia que seriam os usineiros e grandes proprietários de terra.

Nesse período, o Estado tem uma presença fortíssima no processo de crescimento econômico das unidades agroindustriais canavieiras, além da consolidação e expansão do capital canavieiro. Daí em diante, passou a amparar "jurídico-institucional-assistencialmente" o setor, com o surgimento do Estatuto da Lavoura Canavieira em 1941 e, tecnologicamente, com a criação da Estação Experimental da Cana de Araras e do Laboratório de Análises em Piracicaba, ambos no estado de São Paulo (BRAY et al, 2000, p. 14).

A regulamentação por parte do Estado em favor do setor agroindustrial canavieiro veio sendo ampliada, pois em 1971, a Lei no 5.654 e o Decreto no 1.186 revogam vários dispositivos do Estatuto da Lavoura Canavieira e exacerba a concentraçáo empresarial e de terras. Neste decreto, há o estímulo à fusão e a incorporação de unidades canavieiras. Assim, conforme Bray et al (2000, p. 46), foram "legalizados os mecanismos que acelerariam os processos de concentração de terras e rendas no setor agroindustrial canavieiro, embora esses processos de concentração já viessem ocorrendo antes da década de 70". Segundo o autor,

$\mathrm{O}$ apoio estatal não somente acontece com as normatizaçôes, os incentivos fiscais e financiamentos, mas também, através das infraestruturas necessárias para que se desenvolva a produção e o consumo, como portos, aeroportos, rodovias, ferrovias, hidrovias, sistema de comunicação, entre outros. Quanto às imposiçóes internas, essas se realizam nas instituiçôes do Estado brasileiro que se tornaram verdadeiras arenas de conflito de interesses de uma sociedade cada vez mais complexa e desigual (BRAY et al, 2000, p. 46).

A participação do Estado tornou-se imprescindível para o desenvolvimento do setor agroindustrial canavieiro. Incentivos fiscais, financiamentos diversos, investimentos em logística, arrolamentos e securitização de dívidas, são algumas das conveniências tratadas pelo mesmo. Isso demonstra que o Estado difunde a ideia de defesa do agronegócio, em especial do setor agroindustrial canavieiro, quando observamos o boom de crescimento da produçáo de cana-de-açúcar.

O Estado está servindo ao setor agroindustrial canavieiro no que concerne à regulamentação de suas ações e à financiamentos realizados para expandir e consolidar o setor. De acordo com IANNI (2004, p. 18), ele concretiza as determinaçóes do capital, mediando as relaçôes capitalistas, pois estimula a acumulação, a concentração e a centralização de capitais em conformidade com as forças produtivas, interferindo na geopolítica do território.

Assim, evidenciamos algumas mudanças na atuação do Estado no que tange às condiçóes de infraestrutura e o apoio logístico para o setor agroindustrial canavieiro e o agronegócio em geral, que passou a subsidiá-los através de: construção e melhorias de rodovias, ferrovias e hidrovias que dão acesso aos portos brasileiros, facilitando o escoamento da produçáo destinada à exportação; construção de dutos para o transporte do etanol em menor tempo e maior lucratividade possível, ligando o estado de Goiás, passando por Mato Grosso do Sul, São Paulo e Paraná; incentivos fiscais que variam de acordo com a região que está localizada a unidade agroindustrial canavieira; apoio técnico e tecnológico nos institutos 
e empresas estatais que trabalham com a agricultura, em especial a Embrapa; entre outros (DOMINGUES, 2010)

Todo esse aparato estatal tem como fim, dar apoio e suporte às empresas nacionais e internacionais do setor agroindustrial canavieiro, oferecendo maior fluidez à circulação do capital canavieiro, proporcionando, por sua vez, maior competitividade do Brasil em relação ao mercado internacional. Assim, o apoio estatal facilita maior abertura comercial e expansão das exportaçóes do setor.

Desta feita, o Estado proporciona uma reconfiguração territorial aliada à lógica capitalista, que se configura em espaço de produção, reprodução, exploração, extração e acumulação, incentivando tais práticas dentro do seu território.

De acordo com Castro (2013, p. 229-230), a vinculação do capital produtivo com o território é evidente e o globo terrestre está disponível para sua expansão. Para o autor,

[...] As possibilidades logísticas e estratégicas de planejar a produção, aproveitando as vantagens locacionais de uma enorme multiplicidade de lugares, e as possibilidades abertas pela tecnologia e pela organização flexível ampliaram enormemente as escolhas para a localizaçáo da produção. Este espaço produtivo internacionalizado propicia a libertaçáo das pesadas normas e tributos impostos pelos governos nacionais sobre as matrizes das grandes empresas, o que torna este capital cada vez mais desnacionalizado. [...].

Apesar de tais intervençóes, a partir dos anos de 1990, houve a desregulamentação estatal do setor agroindustrial canavieiro, que fortaleceu o sistema organizacional próprio deste, como: União da Indústria Canavieira (UNICA), Coligação das Entidades Produtoras de Açúcar e Álcool (Cepaal), Associação Paulista da Agroindústria Sucroalcooleira (Sucroalco), Brasil Álcool S/A, Bolsa Brasileira de Álcool (BBA), Organizaçáo dos Plantadores de Cana do Estado de São Paulo (Orplana), Conselho de Produtores de Cana, Açúcar e de Álcool de Sáo Paulo (Consecana), Cooperativa dos Plantadores da Cana de Piracicaba (Coplacana), Cooperativa dos Produtores de Açúcar e Álcool do Estado de São Paulo (Copersucar), etc.

Convém destacar que tal desregulamentação por parte do Estado, não significa o seu desaparecimento, como mola propulsora do processo produtivo, ou seja, não o elimina do processo de reprodução do capital, pois a concessão de terras, a taxação de juros e a criação de subsídios para exportação e importação, estão combinadas com um conjunto de políticas produzidas aos interesses do mercado (SOUZA, 2011).

O Estado realiza uma estruturaçáo do território, uma vez que propicia condiçóes adequadas ao pleno desenvolvimento do setor agroindustrial canavieiro, por meio da melhoria em infraestrutura, aportes técnicos, entre outros, enquanto que de outro lado diminui os investimentos na produção de alimentos.

A intervenção estatal produz efeitos duradouros visando à melhoria da competitividade, à criação de um ambiente favorável para o pleno funcionamento das empresas, por meio da infraestrutura econômica e social, estabilidade política, qualificação de máo de obra, financiamentos diversos, etc. "Portanto, embora o capital esteja livre para voar, é o Estado que fornece as condiçóes para o seu pouso, revalorizando o território para manter antigos 
investimentos ou para atrair novos" (CASTRO, 2013, p. 239), como a estabilidade econômica e política ${ }^{4}$.

Nesse cenário, encontramos as lavouras canavieiras em várias partes do país que, nos anos de 2013 e 2014, passavam por uma crise hídrica, devido à falta de chuvas que prejudicou o crescimento e o desenvolvimento dos canaviais 5 . Apesar disso, muitos grupos internacionais que atuam com a agroindústria canavieira nessas regióes vêm se protegendo das crises por meio do apoio estatal. $\mathrm{O}$ apoio se consolida com incentivos fiscais e o perdáo, arrolamento e/ou securitização de dívidas, entre outros.

Observamos que o Estado tem focado o desenvolvimento e expansão do setor agroindustrial canavieiro, pois as regulaçôes, incentivos, isençôes, financiamentos e tantas outras formas de apoio, permitiu que o setor canavieiro resistisse ao tempo. Além disso, novos agentes, como o mercado financeiro, vão tornando essas relaçóes, entre o Estado e este capital, muito mais estreitas, já que há uma regulamentação e normatização do aparelho estatal para atender às necessidades do setor.

Há articulação entre as legislaçóes nos diversos âmbitos, que visa atender o setor agroindustrial canavieiro, bem como a criação de condiçóes para acumulação do capital e o fortalecimento das relações de poder local das unidades agroindustriais canavieiras sob as regiōes onde atuam.

A legislação federal atua mais no sentido de proteção, financiamento e regulamentação do setor, já a legislação estadual, intervém para os incentivos fiscais e, a legislação municipal, ordena no que diz respeito à questão ambiental. Em alguns casos, estas leis se entrelaçam, mas todas permanecem atuando em favor do setor agroindustrial canavieiro. No presente trabalho vamos apresentar e discutir sobre a atuação estatal em âmbito municipal.

\section{ATUAÇÁO ESTATAL NO SETOR AGROINDUSTRIAL CANAVIEIRO NO ÂMBITO DO MUNICÍPIO DE PONTA PORÃ}

A relação entre o governo municipal de Ponta Porã e o setor agroindustrial canavieiro ocorre desde a sua pré-instalação até o pleno funcionamento deste. Várias são as formas de articulação e manutenção do setor no referido município.

O governo municipal da época (Flávio Kayatt 2005-2012) concedeu muitos benefícios para que a unidade agroindustrial Monteverde (Grupo Bunge y Born) se instalasse no município, como incentivos fiscais e todo o serviço de terraplanagem no local onde foi

4 Inúmeros programas de desenvolvimento foram criados ao longo da história do país, visando à integração e estabilidade econômica e criando o clima favorável às empresas, como Programa de Desenvolvimento da Grande Dourados (PRODEGRAN), Programa de Desenvolvimento do Centro-Oeste (PRODOESTE), Superintendência de Desenvolvimento do Centro-Oeste (SUDECO), Superintendência de Desenvolvimento da Amazônia (SUDAM), Superintendência de Desenvolvimento do Nordeste (SUDENE), entre outros.

5 Notícia publicada no Portal G1, do dia 12 de outubro de 2014, intitulada "Seca reduz receita do setor canavieiro em R \$ 54 mi na região, diz Coplacana”, por meio do endereço eletrônico <http://g1.globo.com/sp/piracicabaregiao/noticia/2014/10/seca-reduz-receita-do-setor-canavieiro-em-r-54-mi-na-regiao-diz-coplacana.html >. Acesso em: 31 ago. 2016. 
construída a planta industrial da mesma ${ }^{6}$. Além disso, incluiu a empresa no Indusporã (Lei Complementar No 15, de 2 de julho de 2004), que concede incentivos à industrialização. Com tais incentivos, a referida unidade ficaria isenta do pagamento de taxas, despesas com alvarás e o recolhimento de tributos municipais.

O objetivo principal desta ação, por parte do poder público, era a geração de empregos para o município, uma vez que a empresa afirmava que geraria mais de duas mil novas vagas para a população ponta-poranense ${ }^{7}$. Entretanto, náo foi o que ocorreu, devido à proximidade da planta industrial com o município de Dourados. O governo municipal não imaginava que isso aconteceria, pois havia a preocupação com a empregabilidade de pessoas de Ponta Porã e a empresa se mostrou comprometida com a administraçáo municipal em 2008 no que concerne ao oferecimento de tais empregos.

Ao entrevistarmos a atual administração (2013 - 2016), como a Secretaria de Indústria, Comércio, Turismo e Meio Ambiente de Ponta Porã $\tilde{a}^{8}$, houve o reconhecimento de que a Unidade Agroindustrial Monteverde não cumpriu com o acordo de geração de empregos à população do município. Foram feitos investimentos por parte do governo municipal, porém a unidade canavieira não deu retorno aos munícipes, destinando a maior parte das vagas para o município de Dourados.

Houve um dispêndio amplo de forças, por parte do governo municipal para a implantaçáo desta unidade canavieira e o retorno ao município foi mínimo, uma vez que, esta unidade tem relaçóes comerciais e geração de empregos com Dourados, conforme as palavras do Secretário de Indústria, Comércio, Turismo e Meio Ambiente de Ponta Porã. "A única vantagem da usina é a arrecadação de ISS" (Imposto Sobre Serviço). E completa:

[...] eu acredito que isso é [...] aquele incentivo fiscal inicial, é justamente, prevendo uma [...], um incremento né na arrecadação de tributos aí do município, no ISS, [...] a usina tá distante $80,90 \mathrm{~km}$ do [...] da sede do município, e o problema que o município tem, Ponta Porã tem, é justamente isso, a mão de obra não é de Ponta Porâ, a mão de obra é de Dourados, porque a usina tá muito mais próximo de Dourados do que de Ponta Porã, e não é só a mão de obra, essa, braçal, é não, é a própria estrutura administrativa, não tem gente daqui trabalhando, não tem ninguém daqui, [...] pode tê um gato pingado aí de gente trabalhando lá mais eu não conheço ninguém. Todo mundo é de Dourado [...]. (Entrevista do dia 18 de setembro de 2015).

Deste modo, aconteceu que a empresa pensou apenas como diminuir custos e começou a contratar trabalhadores que residiam em Dourados. Isso não era esperado por parte do

6 Notícia intitulada: “Usina de Ponta Porã vendida à Bunge”, do dia 17 de setembro de 2008 no Diário MS, no endereço eletrônico <http://diarioms.com.br/usina-de-ponta-pora-vendida-a-bunge/>. Acesso em 22 fev. 2015.

7 Informação obtida por meio do Portal Jornal Cana, do dia 24 de outubro de 2006, com o título "Grupo do RS vai implantar usina de açúcar e álcool em Ponta Porâ”, no endereço eletrônico: <https://www.jornalcana.com.br/ grupo-do-rs-vai-implantar-usina-de-acucar-e-alcool-em-ponta-pora/>. Acesso em 02 set. 2016.

8 Entrevista realizada no dia 18 de setembro de 2015, com o R. F. e F. P.

9 Entrevista realizada no dia 18 de setembro de 2015, com A. C. Q. na Secretaria de Agricultura e Abastecimento do Município de Ponta Porá. 
governo municipal de Ponta Porã que concedeu inúmeras vantagens à unidade agroindustrial Monteverde. Esta conjuntura demonstra que a empresa está focada apenas na acumulaçáo de capital.

Em entrevista com o Sindicato dos Trabalhadores Rurais de Ponta Porã (Sr. O. M. G. ${ }^{10}$, a mão-de-obra utilizada na agroindústria canavieira vem diminuindo ao longo dos anos, em virtude, da mecanização do plantio e da colheita da cana-de-açúcar na região e da contratação de mão-de-obra de pessoas que moravam em Dourados e não em Ponta Porá, por conta da proximidade com a unidade canavieira e, consequentemente, a diminuição com gastos de transporte.

Em 2007, o número de trabalhadores que estavam atuando na agropecuária era de 700 pessoas, a maior quantidade de pessoas empregadas nesse ramo, que correspondeu ao período de plantio da cana-de-açúcar para a formação dos canaviais necessários às primeiras moagens na planta industrial. Nos anos subsequentes, apresentou queda, tendo como um dos seus motivos as contrataçóes realizadas de trabalhadores que moram em Dourados.

$\mathrm{Na}$ área industrial o quadro se repete, uma vez que, no ano de instalação da unidade agroindustrial Monteverde (2007), o número de admissóes passava de 200 pessoas, chegando a ter mais de 700 entradas para o setor em 2010, mas, em 2015, apresentava apenas 150 vagas de admissão. Todo esse cenário, demonstra o quadro de ilusão criado pela unidade canavieira, que em seu discurso geraria cerca de 3 mil empregos diretos e indiretos em Ponta Porã, quando, na verdade, estão mudando o quadro de funcionários para trabalhadores de Dourados $^{11}$.

No ano de 2015, a Unidade Monteverde, reforçou a intenção de diminuir os trabalhadores que estivessem residindo em Ponta Porã para contratar pessoas que estivessem morando em Dourados, com o intuito claro de reduzir gastos com transporte. Para funcionários que já estavam trabalhando na empresa e estivesse residindo em Ponta Porã, foi sugerido que o mesmo se mudasse para a cidade vizinha ${ }^{12}$.

Houve pressão por parte da empresa para que os funcionários que moravam em Ponta Porã mudassem para Dourados, de acordo com a entrevistada E. B. S. A mesma residia no primeiro município e foi chamada pelo chefe de setor, a considerar a mudança para Dourados, com a alegação de que seria melhor, pois não demoraria tanto tempo para chegar ao local de trabalho. Como seu marido estava desempregado resolveu se mudar ${ }^{13}$.

No entanto, a própria afirmou que muitos de seus colegas de trabalho que não mudaram acabaram sendo despedidos. A empresa não concedeu entrevista a respeito. Mas de acordo,

10 Entrevista realizada no dia 18 de setembro de 2015, no Sindicato dos Trabalhadores Rurais do município de Ponta Porã/MS.

11 Informação adquirida no Portal Jornal Cana, do dia 14 de setembro de 2009, com o título "Usina Monteverde inicia testes de moagem em Ponta Porâ, MS", por meio do site: <https://www.jornalcana.com.br/usina-monteverde-inicia-testes-de-moagem-em-ponta-pora-ms/>. Acesso em 05 set. 2016.

12 Notícia do Portal Conesul News, do dia 25 de setembro de 2015, intitulada "Usina estaria disposta a demitir funcionários de Ponta Porâ”. Endereço eletrônico <http://www.conesulnews.com.br/cidade/usina-estariadisposta-a-demitir-funcionarios-de-ponta-pora>. Acesso em 05 set. 2016. 
com C. R. $\mathrm{S}^{14}$, que já havia trabalhado na referida unidade agroindustrial canavieira, essa situação vinha ocorrendo desde 2014, quando esta ainda fazia parte do Grupo Bunge y Born.

Desta feita, o capital canavieiro encontra formas diversas de ampliação e acumulação, atingindo a parte mais fraca dessa corrente, que é o trabalhador, que muitas vezes para continuar vendendo sua força de trabalho e existindo, aceita a submissão imposta pela empresa, que além de extrair a mais-valia, passa a diminuir os custos com transporte, sem levar em consideração os anseios dos trabalhadores.

Com relação à questão ambiental, a responsabilidade de fiscalizar e expedir o Licenciamento Ambiental eram do Instituto do Meio Ambiente de Mato Grosso do Sul (IMASUL) até o ano de 2012. Após esse ano, essa responsabilidade foi repassada aos municípios sul-mato-grossenses. Assim, Ponta Porã assume a administração da organização ambiental de sua área municipal. Quando se responsabilizou por esta atividade a unidade agroindustrial Monteverde já havia sido instalada, tendo toda a análise ambiental sendo realizada pelo órgão estadual.

$\mathrm{Na}$ atualidade, o papel do governo municipal, é de emitir um certificado após análises ambientais, para autorizaçáo de instalação de qualquer empreendimento. Também, avaliam a questão da licença já emitida anteriormente, pelo IMASUL, para rever se as empresas têm ou não que fazer alguma ação ambiental que minimize os impactos que possivelmente foram causados, como desmatamento indevido, assoreamento de rios, destruição de fauna e flora, etc.

De acordo com, R. F. (Secretário de Indústria, Comércio, Turismo e Meio Ambiente de Ponta Porãa ${ }^{15}$, o sistema de gestão ambiental da unidade agroindustrial Monteverde é falho e não há preocupação, por parte do gestor da mesma, que na maioria das vezes, não são formados, para fazer um planejamento de recuperaçáo de nascentes, replantio de matas ciliares, etc., por motivo de corte de custos. E completa:

[...] O setor canaviário está atrasado é, traz benefícios socioeconômicos é, mas não traz benefícios socioambientais né, [...] melhora a qualidade de vida da população economicamente é, mas, é prejudica né, a parte ambiental do nosso município, pois os impactos são grandes né, por exemplo, tem a perda de nutrientes do solo né, tem a compactação do solo né, quando eles usa aquelas máquinas pesadas, aí compacta né, tem o uso intenso de pesticida e herbicida que prejudica a produção dos vizinhos e, também, infiltra com a chuva né, no solo e, contamina o lençol freático, tem tamém a contaminação de óleo diesel que abastece os maquinário deles, que polui os corpo hídrico e o solo né, e o a emissão de gases 24 horas pela chaminé da usina né16.

\footnotetext{
14 Idem.

15 Entrevista realizada na Secretaria de Indústria, Comércio, Turismo e Meio Ambiente de Ponta Porã, no dia 18 de setembro de 2015.

16 Idem.
} 
Em suma, o governo municipal fiscaliza muitos empreendimentos dentro do seu limite político-administrativo e percebemos, nas falas dos entrevistados, que o setor canavieiro é um dos mais poluentes quando se trata de questão ambiental. No entanto, tal governo, defende a implantação de uma empresa desse porte por conta do aumento de tributos que o município passa a receber e, assim, poder administrar com mais recursos áreas deficitárias, como saúde e educação.

Há, também, em Dourados, uma espécie de atração de investidores de todos os segmentos do setor agroindustrial canavieiro, com o apoio da administração atual do município (2013-2016) e a criação do Polo de Serviços do Setor Sucroenergético de Dourados e Região, que tem como objetivo principal a prestação de serviços para unidades canavieiras de toda a regiáo da "Grande Dourados" (um total de 16 unidades agroindustriais próximas), no intuito de criar oportunidades de empregos no âmbito do município de Ponta Porâa ${ }^{17}$.

Segundo a Sra. E. R. S., o foco não é atrair mais unidades agroindustriais canavieiras e sim prestar serviços para as já existentes, criando uma rede de atendimento ao setor agroindustrial, buscando evitar que estas adquiram peças e equipamentos em outros estados, principalmente em São Paulo ${ }^{18}$. Visualizamos com essa ação do município de Dourados, que a intenção é atrair investimentos de outras empresas para si não deixando que as mesmas se desenvolvam em Ponta Porâ, ou qualquer município próximo.

Para a administração de Ponta Porã, isso pode gerar ainda mais desemprego, uma vez que os trabalhadores da planta industrial e do campo da Unidade Monteverde, em sua maioria, já residem em Dourados, e, com a vinda das empresas prestadoras de serviços para a segunda cidade, amplia-se a ociosidade da mão de obra no primeiro município.

Enfim, o papel do Estado representado na esfera municipal, se reduz a incentivos fiscais, fiscalização ambiental, entre outros, quando na verdade, deveria agir como mediador dos conflitos entre fornecedores e industriais, levando em consideração as questóes de emprego e renda em detrimento dos elevados ganhos e acumulaçáo de capital por meio da atividade agroindustrial canavieira.

Já para as esferas estaduais e federal, a atuação principal deveria ser o impedimento da existência ou criação de monopólios e não o seu acirramento, que tem como objetivo ampliar o poder de mercado e, consequentemente, a influência sobre determinadas porçóes do território, criando redes de poder econômico do setor canavieiro e aumentando o desenvolvimento desigual e combinado das unidades canavieiras.

17 Entrevista realizada no dia 10 de outubro de 2014, na Secretaria Municipal de Desenvolvimento Econômico Sustentável, com a Sra. E. R. S.

18 Esse fato aconteceu na 4a Feira Agro Metal de Mato Grosso do Sul. Na região de Dourados estão localizadas 16 usinas, produzindo açúcar, etanol e bioenergia. A 4a Feira Agrometal do Mato Grosso do Sul, a vitrine que mostra o desenvolvimento do setor sucroenergético em Mato Grosso do Sul, reuniu 60 expositores locais, de São Paulo, Paraná, Santa Catarina, Minas Gerais e outros estados, que apresentaram seus produtos para a indústria, comércio, serviços e agricultura. Informação obtida por meio da notícia "APL Metal mecânico, criado por Murilo, melhora resultados a cada ano", de 20 de outubro de 2014, no endereço eletrônico <http://www.feiraagrometal. com.br/index.php/a-feira/>. Acesso em 20 fev. 2016. 
O Estado é um parceiro do capital canavieiro e age em conformidade com as necessidades desse setor, uma vez que estimulou o avanço do capital canavieiro em áreas com nenhuma tradição nesse tipo de produção, como o município de Ponta Porã. Por ser parceiro, estimula também a acumulação e centralização de capital, explorando a força de trabalho local de diversos sujeitos, para extrair a mais-valia. Assim mantém as relaçóes de poder sob porçóes concentradas do território, acirrando conflitos de classe já existentes, como o dos proprietários de terras x camponeses e trabalhadores assalariados.

\section{ALGUMAS CONSIDERAÇÓES}

Visualizamos que o Estado capitalista brasileiro não tem medido esforços para financiar esses projetos de territorialização do capital no campo viabilizando sua expansão econômica e territorial. Isso reflete numa disputa territorial em curso entre os diversos sujeitos como capitalistas e proprietários de terra, de um lado e os camponeses de outro. Essa disputa é desigual, uma vez que, de um lado os capitalistas e os proprietários de terras (mesmo tendo objetivos distintos, um quer o lucro e o outro a renda da terra), aliam-se com o Estado, enquanto do outro lado, os camponeses, ficam subjugados ao avanço das relaçóes capitalistas e de poder, restando-lhes a resistência a esse modelo de desenvolvimento e acumulaçáo de capital.

O Estado tem sido um aliado essencial do setor agroindustrial canavieiro, dado o volume expressivo de recursos, demonstrando o seu caráter classista que atende com presteza os interesses da classe dominante. Esses investimentos vêm fortalecendo as estratégias do capital canavieiro no município de Ponta Porã, uma vez que há aquisições de novas unidades, fusóes, e novos projetos para a produçáo no setor, reorganizando a produção no campo. Desta forma, o papel do Estado está sendo o de agente dinamizador do território ponta-poranense.

Também tem dado o suporte necessário para a mobilidade geográfica do capital canavieiro por meio de um conjunto de infraestruturas físicas como portos, aeroportos, rodovias, ferrovias, hidrovias, etc., objetivando assegurar as trocas comerciais e/ou a ampliaçáo da acumulação de capital. Nesse ínterim, a participação do Estado brasileiro, em todos os âmbitos, tornou-se indispensável para o desenvolvimento do setor agroindustrial canavieiro.

Quanto ao setor canavieiro em Ponta Porã, o papel do Estado, desdobra-se em incentivos fiscais, fiscalizaçáo ambiental, e doação de áreas para implantaçáo das unidades processadoras. Portanto, o Estado é um parceiro do capital canavieiro e age em conformidade com as necessidades desse capital, uma vez que estimulou seu avanço em áreas com nenhuma tradição nesse tipo de produção como o município de Ponta Porã. 


\section{REFERÊNCIAS}

ACQUAVIVA, Marcus Cláudio. Teoria Geral do Estado. São Paulo: Saraiva, 2000.

BRASIL. Lei no 5.654, de 14 de maio de 1971. Aprova a Estrutura Regimental e o Quadro Demonstrativo dos Cargos em Comissáo e das Funçóes Gratificadas do Ministério do Meio Ambiente, e dá outras providências. Diário Oficial da Presidência da República, Casa Civil, Brasília, DF, 1971.

CONESUL NEWS. Usina estaria disposta a demitir funcionários de Ponta Porã. Acesso em: <http://www.conesulnews.com.br/cidade/usina-estariadisposta-a-demitir-funcionarios-de-ponta-pora>. Acesso em 05 de set. 2016.

DIÁRIO MS. Usina de Ponta Porã vendida à Bunge. Disponível em: <http://diarioms. com.br/usina-de-ponta-pora-vendida-a-bunge>. Acesso em 22 de fev. 2015.

DOURADOS. APL Metal mecânico, criado por Murilo, melhora resultados a cada ano. Disponível: <http://www.feiraagrometal.com.br/index.php/a-feira/>. Acesso em $20 \mathrm{de}$ fev. 2016.

JORNAL CANA. Grupo do RS vai implantar usina de açúcar e álcool em Ponta Porã. Disponível em: <<https://www.jornalcana.com.br/grupo-do-rs-vai-implantar-usina-de-acucar-e-alcool-em-ponta-pora/>. Acesso em 02 de set. 2016.

JORNAL CANA. Usina Monteverde inicia testes de moagem em Ponta Porá, MS. Disponível: <https://www.jornalcana.com.br/usina-monteverde-inicia-testes-de-moagem-em-ponta-pora-ms/>. Acesso em: 05 de fev. 2016.

BRASIL. Decreto-Lei no 1.186, de 27 de agosto de 1971. Concede estímulos à fusão, incorporação e relocalização de unidades industriais açucareiras e dá outras providências. Diário Oficial da Presidência da República, Casa Civil, Brasília, DF, 1971.

BRAY, Silvio Carlos; FERREIRA, Enéas Rente; RUAS, Davi Guilherme Gaspar. As Políticas da Agroindústria Canavieira e o Proálcool no Brasil. Marília-SP: Unesp Marília, 2000.

CASTRO, I. E. de. Geografia e Política: território, escalas de ação e instituições. Rio de Janeiro, Bertrand Brasil, 2013.

DOMINGUES, Alex Torres. A territorializaçáo do grupo agroindustrial canavieiro Louis Dreyfus no Mato Grosso do Sul. 2010. 200 f. Dissertação (Mestrado em Geografia). Faculdade de Ciências Humanas da Universidade Federal da Grande Dourados, Dourados, 2010 .

HARVEY, David. A produçáo capitalista do espaço. São Paulo: Annablume, 2005.

HARVEY, David. O neoliberalismo: história e implicaçóes. São Paulo: Ediçóes Loyola, 2012.

IANNI, Octávio. Dialética e Capitalismo. Petrópolis/RJ: Vozes, 1988.

IANNI, Octavio. Estado e capitalismo segundo Engels. Marx e Engels na História. Humanitas, 1996. Org. Osvaldo Coggiola.

IANNI, Octavio. Estado e capitalismo. São Paulo: Brasiliense, 2004. 
MARX, Karl; ENGELS, Friedrich. A Ideologia Alemã. São Paulo: WMF Martins Fontes, 2001.

MATO GROSSO DO SUL. Lei Complementar no 93, de 05 de novembro de 2001. Institui o Programa Estadual de Fomento à Industrializaçáo, ao Trabalho, ao Emprego e à Renda (MS Empreendedor) e dá outras providências. Diário Oficial do Estado de Mato Grosso do Sul, Campo Grande/MS, 2001.

MORAES, Márcia Azanha Ferraz Dias de. A desregulamentaçáo do Setor Sucroalcooleiro do Brasil. Americana/SP: Caminho Editorial, 2000.

POULANTZAS, Nico. O Estado, o poder, o socialismo. São Paulo: Graal, 2000.

SAES, Décio. Capitalismo e processo político no Brasil. São Paulo: Boitempo, 2001.

SOUZA, Sônia Maria Ribeiro. A emergência do discurso do agronegócio e a expansáo da atividade canavieira: estratégias discursivas para a açáo do capital no campo. 2011. 275f. Tese (Doutorado em Geografia) - Faculdade de Ciência e Tecnologia da Universidade Estadual Paulista "Júlio de Mesquita Filho", Presidente Prudente/SP, 2011.

THERBORN, Goran. As teorias do Estado e seus desafios no fim de século. In: SADER, Emir; GENTILI, Pablo (orgs.). Pós-Neoliberalismo II: que Estado para que democracia? Petrópolis/RJ: Vozes, 1999.

Recebido para publicação em junho de 2017

Aceito para publicação em janeiro de 2018 